\title{
Whole-Body Evaluation of MIBG Tissue Extraction in a Mouse Model of Long-Lasting Type II Diabetes and Its Relationship with Norepinephrine Transport Protein Concentration
}

\author{
Claudia Kusmic ${ }^{1}$, Silvia Morbelli ${ }^{2}$, Cecilia Marini ${ }^{1}$, Marco Matteucci ${ }^{3}$, Chiara Cappellini ${ }^{3}$, Elena Pomposelli ${ }^{2}$, \\ Paolo Marzullo ${ }^{1}$, Antonio L'Abbate ${ }^{1,3}$, and Gianmario Sambuceti ${ }^{2}$ \\ ${ }^{I}$ Institute of Clinical Physiology CNR, Pisa, Italy ${ }^{2}$ Department of Internal Medicine, Division of Nuclear Medicine, University of Genoa, \\ Genova, Italy; and ${ }^{3}$ Scuola Superiore Sant'Anna, Pisa, Italy
}

\begin{abstract}
Accelerated cardiac washout of ${ }^{123}$-metaiodobenzylguanidine (MIBG), which is clinically used as an index of cardiac neuropathy in diabetes, is ascribed to decreased norepinephrine reuptake into synaptic vesicles. However, accelerated washout frequently contrasts with preserved early tracer uptake, whose significance remains undetermined. The aim of this study was to investigate in a mouse model of long-lasting type II diabetes whether the mismatch between MIBG early uptake and washout is the consequence of a more generalized disorder of the autonomic nervous system. Methods: Nine mice were given low doses of streptozotocin by intraperitoneal injection for 5 consecutive days. At 7 mo after streptozotocin, MIBG kinetics were evaluated by heart and liver time-activity curves and by tracer accumulation in the bladder. Data were compared with those obtained in 10 sham mice and correlated with the cardiac and hepatic tissue expression of norepinephrine transporter (NET) as assessed with a ${ }^{3} \mathrm{H}$-desipramine saturation binding assay. Results: In diabetic mice, myocardial and liver MIBG retention was reduced at $2 \mathrm{~h}$ and was associated with both increased tracer washout and reduced NET density. The rate of myocardial washout correlated with the degree of urinary MIBG excretion. Conclusion: The paradoxic observation of preserved early uptake associated with accelerated washout of MIBG in diabetes seems to be explained by a generalized disorder in NET function leading to reduced whole-body tracer removal from the blood and increased tracer availability for early myocardial uptake.
\end{abstract}

Key Words: type II diabetes; cardiac autonomic neuropathy; SPECT; radiobinding, mouse

J Nucl Med 2008; 49:1701-1706

DOI: 10.2967/jnumed.108.054361

$\mathbf{C}$ complication of diabetes that markedly impairs the quality of

Received May 15, 2008; revision accepted Jun. 20, 2008.

For correspondence or reprints contact: Claudia Kusmic, Area della Ricerca CNR, Istituto di Fisiologia Clinica, Via Moruzzi, 1-56124 Pisa, Italy. E-mail: kusmic@ifc.cnr.it

COPYRIGHT ( 2008 by the Society of Nuclear Medicine, Inc. life and causes a 3- to 10-fold increase in the 5-y mortality rate, reaching values as high as $16 \%-53 \%(1-5)$. Despite this relevant prognostic impact, the diagnosis of cardiac autonomic neuropathy is hardly ever addressed, likely because of the lack of standardized diagnostic criteria and methodologies.

Recently, imaging of ${ }^{123}$ I-metaiodobenzylguanidine (MIBG) myocardial retention by SPECT has been clinically introduced to investigate the function of sympathetic neuronal endings $(6-8)$. Once carried to the nervous terminals, the tracer is taken up by cardiac sympathetic neurons and stored in adrenergic vesicles via a specific norepinephrine transporter (NET) (9-15). Using this tool, several clinical studies $(4,5,16,17)$ documented an accelerated tracer washout from the heart that was experimentally found to be an index of impaired norepinephrine reuptake due to reduced NET expression in the diabetic myocardium (18-20). Most of these studies, however, also reported that such an accelerated cardiac loss of MIBG was associated with a relatively preserved initial uptake in most diabetic patients $(4,5,16,17)$, especially when tracers with high specific activity were used (21). This apparent paradox has never been conclusively explained despite the generally accepted assumption that both uptake and reuptake of MIBG are regulated by the same mechanism, that is, the NET protein function.

In the present study, we tested the hypothesis that the discrepancy between MIBG uptake and MIBG washout might be a methodologic artifact related to a higher tracer bioavailability for neuronal exchange in diabetes (namely a higher blood concentration). The rationale for this hypothesis was the well-known concept that cardiac autonomic neuropathy, a subtype of peripheral diabetic polyneuropathy, might be associated with a disorder of the autonomic nervous system as a whole (22). This possibility would imply a generalized reduced uptake of MIBG from the various organs and thus its persistence in the bloodstream.

On the basis of these considerations, the present study was designed to verify, in a mouse model of long-lasting 
type II diabetes, whether underexpression of NET selectively affects the myocardium or also involves other organs and whether this abnormality can be derived by whole-body imaging of the MIBG time course.

\section{MATERIALS AND METHODS}

\section{Chemicals}

${ }^{123} \mathrm{I}-\mathrm{MIBG}$ was supplied by Amersham Health. ${ }^{3} \mathrm{H}$-desipramine (2.75 TBq/mmol) was purchased from PerkinElmer Life Science. Desipramine was purchased from Sigma Aldrich. All other chemicals were of reagent grade.

\section{Animals}

Surgical procedures and experimental protocols were approved by the Animal Care Committee of the Ministry of Health and conformed with the "Guiding Principles for Research Involving Animals and Human Beings" approved by the Council of the American Physiologic Society.

Nine male C57BL/6 4-wk-old mice weighing a mean ( \pm SEM) of $17.8 \pm 0.2 \mathrm{~g}$ (Charles River) were given a low-dose intraperitoneal injection of streptozotocin to induce moderate diabetes, by adapting the protocol used by members of the Animal Models of Diabetic Complication Consortium $(23,24)$. Briefly, streptozotocin was freshly dissolved daily in citrate buffer $(0.05 \mathrm{~mol} / \mathrm{L}, \mathrm{pH} 4.4)$ at a concentration of $5 \mathrm{mg} / \mathrm{mL}$ and injected intraperitoneally at a dose of $35 \mathrm{mg} / \mathrm{kg}$ of body weight for 5 consecutive days. Ten mice matched for age and sex to the control mice (body weight, $18.3 \pm$ $1.1 \mathrm{~g}$ ) were treated by citrate buffer solution only. All mice were housed for $7 \mathrm{mo}$ and given food and water ad libitum. Blood samples were collected weekly from the tail vein of mice kept fasting for $4 \mathrm{~h}$ to measure glucose levels by the glucose oxidase method (Glucocard GT-1610; Menarini Diagnostics). Insulin levels were determined by the enzyme-linked immunosorbent assay method (Mouse Insulin ELISA; Mercodia) in serum samples collected before drug treatment (basal level) and at the time of animal sacrifice.

Animals randomly chosen from the 2 groups underwent glucose tolerance testing by measuring the clearance of an intraperitoneally injected glucose load. The test was performed on awake mice that had been kept fasting for $6 \mathrm{~h}$ and were injected with glucose solution. A stock solution of $100 \mathrm{mg}$ of glucose per milliliter was prepared in distilled water and sterilized by being passed through a $0.2-\mu \mathrm{m}$ filter into a sterile bottle. After the baseline blood glucose measurement, the mice were challenged with a glucose load of $1 \mathrm{mg}$ of glucose per gram of body weight. Blood glucose measurements were performed at 10, 20, 30, 60, and $120 \mathrm{~min}$ after glucose loading.

\section{In Vivo Imaging}

With the mice under anesthesia with pentobarbitone sodium ( $40 \mathrm{mg} / \mathrm{kg}$ intraperitoneally), the right jugular vein was cannulated with a 30-gauge cannula and the animals were positioned under the head of a large-field $\gamma$-camera (Millennium MG; GE Healthcare) equipped with a pinhole collimator. The window energy was centered over the $159-\mathrm{keV}$ photopeak of ${ }^{123} \mathrm{I}$, and the frame matrix was set at $128 \times 128$ pixels. To guarantee the absence of urination during acquisition, the penile urethra of the mice was cannulated with a 28-gauge polyethylene catheter equipped with a blocking cover. Thereafter, $37 \mathrm{MBq}$ of ${ }^{123}$ I-MIBG diluted in $150 \mu \mathrm{L}$ of saline were injected, soon after the start of a dynamic acquisition $(60 \times 1 \mathrm{~s}, 8 \times 30 \mathrm{~s}$, and $23 \times 300 \mathrm{~s}$ frames, for a total of $120 \mathrm{~min})$.
Both the syringe and the cannula were placed far from the camera immediately after the tracer injection.

The first 68 frames of the dynamic acquisition were reviewed in cine mode to allow better definition of the heart. Regions of interest were thus positioned on the heart, liver, and bladder, and a time-activity curve was obtained expressing region-of-interest counting rate (counts/s) after correction for physical decay of ${ }^{123}$ I. The first 5 min were excluded to avoid contamination of the field of view from residual activity in the injection system. The whole-body counting rate from minute 5 to minute 10 was used to estimate the injected dose. Myocardial and liver counts were thus expressed as the percentage fraction of the injected dose retained in the 2 organs at each time. To minimize interference from blood activity, only data obtained later than $30 \mathrm{~min}$ after the injection were considered for the analysis. Tracer washout was calculated as (counting rate at $30 \mathrm{~min}$ - counting rate at $120 \mathrm{~min}$ )/counting rate at $30 \mathrm{~min}$.

Time-activity curves were drawn to verify the kinetics of tracer clearance from both the myocardium and the liver and to assess tracer accumulation in the bladder.

The 2-h urinary excretion rate (percentage of injected dose) was obtained by measuring the fraction of the dose in the bladder region of interest in the last frame of the 2-h acquisition.

\section{Cardiac and Liver Membrane Preparation}

At the end of the imaging study, the mice, while still under deep anesthesia, were heparinized (500 U intramuscularly) and sacrificed by heart excision. The hearts and livers were washed by buffer perfusion and then were frozen in liquid nitrogen within $10 \mathrm{~min}$ from explantation and stored at $-80^{\circ} \mathrm{C}$.

For membrane preparation, the hearts and livers were cut into pieces with a scalpel, resuspended in 10 volumes of ice-cold lysis buffer (Tris- $\mathrm{HCl}[5 \mathrm{mmol} / \mathrm{L}, \mathrm{pH}$ 7.4] and ethylenediaminetetraacetic acid $[2 \mathrm{mmol} / \mathrm{L}])$, and homogenized in a Potter tissue mincer. The homogenate was centrifuged at $800 \mathrm{~g}$ for $10 \mathrm{~min}$ to remove cell debris and nuclei, and the supernatant was centrifuged twice at $45,000 \mathrm{~g}$ for $50 \mathrm{~min}$. The resulting membrane pellet was resuspended in a buffer containing Tris- $\mathrm{HCl}(50 \mathrm{mmol} / \mathrm{L}, \mathrm{pH} 7.5)$, $\mathrm{NaCl}(120 \mathrm{mmol} / \mathrm{L})$, and $\mathrm{KCl}(5 \mathrm{mmol} / \mathrm{L})$, and stored at $-80^{\circ} \mathrm{C}$ until use. Protein concentration was determined according to Pierce's protein assay using bicinchoninic acid.

\section{Radioligand Binding for NET Protein}

Incubation of membranes with ${ }^{3} \mathrm{H}$-desipramine in concentrations ranging from 0.5 to $35 \mathrm{nmol} / \mathrm{L}$ was performed in Tris- $\mathrm{HCl}$ $(50 \mathrm{mmol} / \mathrm{L}, \mathrm{pH} 7.5), \mathrm{NaCl}(120 \mathrm{mmol} / \mathrm{L})$, and $\mathrm{KCl}(5 \mathrm{mmol} / \mathrm{L})$, with or without desipramine $(100 \mathrm{mmol} / \mathrm{L})$, to define nonspecific binding, for $45 \mathrm{~min}$ at $25^{\circ} \mathrm{C}$ in a volume of $500 \mu \mathrm{L}$. On average, $150 \mu \mathrm{g}$ of protein per tube were used. The addition of $5 \mathrm{~mL}$ of ice-cold incubation buffer and rapid filtration through Whatman GF/F fiber filters with a 36-channel cell harvester terminated the binding. Finally, each filter was rinsed 3 times with $5 \mathrm{~mL}$ of ice-cold buffer. Filter radioactivity was determined by liquid scintillation counting in a TRI-CARB $\beta$-counter (CanberraPackard).

The equilibrium dissociation constant $\left(\mathrm{K}_{\mathrm{D}}\right)$ and the maximal specific binding $\left(\mathrm{B}_{\max }\right)$ were determined from Scatchard plots and analyses of the counting data. The binding was fully saturable and showed a linear dependence on the amount of membrane protein used. Specific binding depended on the presence of sodium ions and was not detectable in the absence of sodium. Optimum 
binding was achieved at a concentration ranging from 100 to 125 mmol of $\mathrm{NaCl}$ per liter. Specific binding was completely inhibited by saturating concentrations of desipramine, as described in the literature (25). The coefficient of variation between repeated measurements in the same batch of tissue sample was less than $5 \%$ in all cases.

\section{Statistical Analysis}

Data are presented as mean values with SEMs. Comparisons within groups were performed using the Student $t$ test. A value of $P$ less than 0.05 was considered statistically significant.

\section{RESULTS}

\section{Characteristics of Animals}

Table 1 summarizes the body weights, plasma glucose levels, and plasma insulin levels of the diabetic and control mice, measured 7 mo after streptozotocin treatment. Plasma glucose levels in diabetic mice were significantly higher than the corresponding values in control mice both at baseline and $2 \mathrm{~h}$ after the challenge $(P<0.005)$. Conversely, there was no significant difference in body weight or plasma insulin level between control and diabetic mice. Heart weight was similar in diabetic and control mice (heart/body weight of $0.005735 \pm 0.0007$ vs. $0.005672 \pm$ 0.0001 in diabetic and control mice, respectively).

\section{In Vivo Imaging}

In 5 mice ( 3 control and 2 diabetic), tracer injection was suboptimal, as a jugular hot spot remained visible in the first image. These experiments were not included in the analysis. In the remaining animals, injected dose was similar in the 2 groups (Table 2). In the same way, the percentage dose retained in the myocardium and liver 30 min after tracer injection was similar in control and diabetic mice (Tables 2 and 3). Conversely, the percentage of myocardial and liver washout was markedly and consistently higher in diabetic than in control mice (Tables 2 and 3).

As shown in Figures 1 and 2, tracer washout from minute 30 to minute 120 showed monoexponential behavior. Fitting of the curves was characterized by a high $r$ value (ranging from 0.962 to 0.997 both for myocardium and for liver). Urinary excretion was remarkably higher in diabetic animals than in control ones (Fig. 3; Table 3). Finally,

TABLE 1

General Characteristics of Experimental Animals

\begin{tabular}{|c|c|c|}
\hline Characteristic & $\begin{array}{l}\text { Control } \\
(n=10)\end{array}$ & $\begin{array}{l}\text { Diabetes } \\
(n=9)\end{array}$ \\
\hline Body weight (g) & $32 \pm 18$ & $34 \pm 12$ \\
\hline Plasma glucose (mg/dL) & $137 \pm 6.7$ & $232 \pm 21$ \\
\hline $\begin{array}{l}\text { Plasma glucose at } 2 \mathrm{~h} \text { after } \\
\text { glucose loading test (mg/dL) }\end{array}$ & $161 \pm 5$ & $368 \pm 27^{*}$ \\
\hline Plasma insulin $(\mu \mathrm{g} / \mathrm{L})$ & $0.9 \pm 0.3$ & $1.2 \pm 0.30$ \\
\hline \multicolumn{3}{|c|}{$\begin{array}{l}{ }^{*} P<0.005 \\
\text { Values are mean } \pm \text { SEM; } n=\text { number of tested animals. }\end{array}$} \\
\hline
\end{tabular}

TABLE 2

Injected Dose and Myocardial Kinetics

\begin{tabular}{lcc}
\hline \multicolumn{1}{c}{ Parameter } & $\begin{array}{c}\text { Control } \\
(n=7)\end{array}$ & $\begin{array}{c}\text { Diabetes } \\
(n=7)\end{array}$ \\
\hline $\begin{array}{l}\text { Whole-body counts at } \\
30 \text { min (counts/s) }\end{array}$ & $816 \pm 92$ & $850 \pm 137$ \\
$\%$ dose in myocardium \\
$\quad$ at 30 min \\
$\begin{array}{l}\% \text { myocardial washout from } \\
\text { minute } 30 \text { to minute } 120\end{array}$ & $21 \pm 4$ & $41 \pm 7^{*}$ \\
& & \\
\hline${ }^{*} P<0.001$. & \\
Values are mean \pm SEM; $n=$ number of tested animals.
\end{tabular}

MIBG washout from the heart correlated loosely with urinary excretion of the tracer as measured by bladder counting ( $r=0.73, P<0.01$; Fig. 4 ).

\section{Binding Experiments}

We determined the NET density in myocardial and hepatic membranes from control and diabetic mice by analyzing the binding of ${ }^{3} \mathrm{H}$-desipramine to the membranes. The specific binding of ${ }^{3} \mathrm{H}$-desipramine was saturable in the range $0.5-40 \mathrm{nmol} / \mathrm{L}$ in both groups. Scatchard analyses gave straight lines in both groups, indicating a single population of binding sites. As shown in Table 4 , the $\mathrm{B}_{\max }$ index of diabetic mice was about $39.3 \%$ lower than that of the control group $(P<0.05)$ for myocardial membranes: similarly, evaluation of hepatocyte membranes confirmed a significant reduction in NET protein concentration in diabetic animals, with respect to control ones $(18 \%, P<0.05)$, although the degree of reduction was less evident that that observed in heart preparations (Table 4). Finally, there was no significant difference in $K_{D}$ value either between the 2 groups or between the 2 different organs (Table 4).

\section{DISCUSSION}

The major finding of the present study was that, in a murine model of prolonged non-insulin-dependent diabetes, MIBG washout from heart and liver, as well as its urinary excretion, was higher than in control animals and
TABLE 3

Liver Kinetics and Urinary Excretion

\begin{tabular}{lcc}
\hline \multicolumn{1}{c}{ Parameter } & $\begin{array}{c}\text { Control } \\
(n=7)\end{array}$ & $\begin{array}{c}\text { Diabetes } \\
(n=7)\end{array}$ \\
\hline $\begin{array}{l}\text { Two-hour urinary excretion } \\
\text { (\% whole-body dose) }\end{array}$ & $33 \pm 3$ & $44 \pm 2^{*}$ \\
$\%$ dose in liver at 30 min & $9.02 \pm 1.43$ & $8.3 \pm 1.06$ \\
$\%$ liver washout from minute & $20 \pm 4$ & $41 \pm 8^{*}$ \\
30 to minute 120 & & \\
& & \\
\hline${ }^{\star} P<0.01$. & \\
Values are mean \pm SEM; $n=$ number of tested animals.
\end{tabular}


FIGURE 1. Myocardial time-activity curves of MIBG, depicted on linear scale (A) and on semilog scale (B). MIBG retention values, expressed as percentage of injected dose, are shown for control (left) and diabetic (right) mice. Early (30 min) uptake was similar for both groups of animals; by contrast, tracer washout was faster in diabetes.

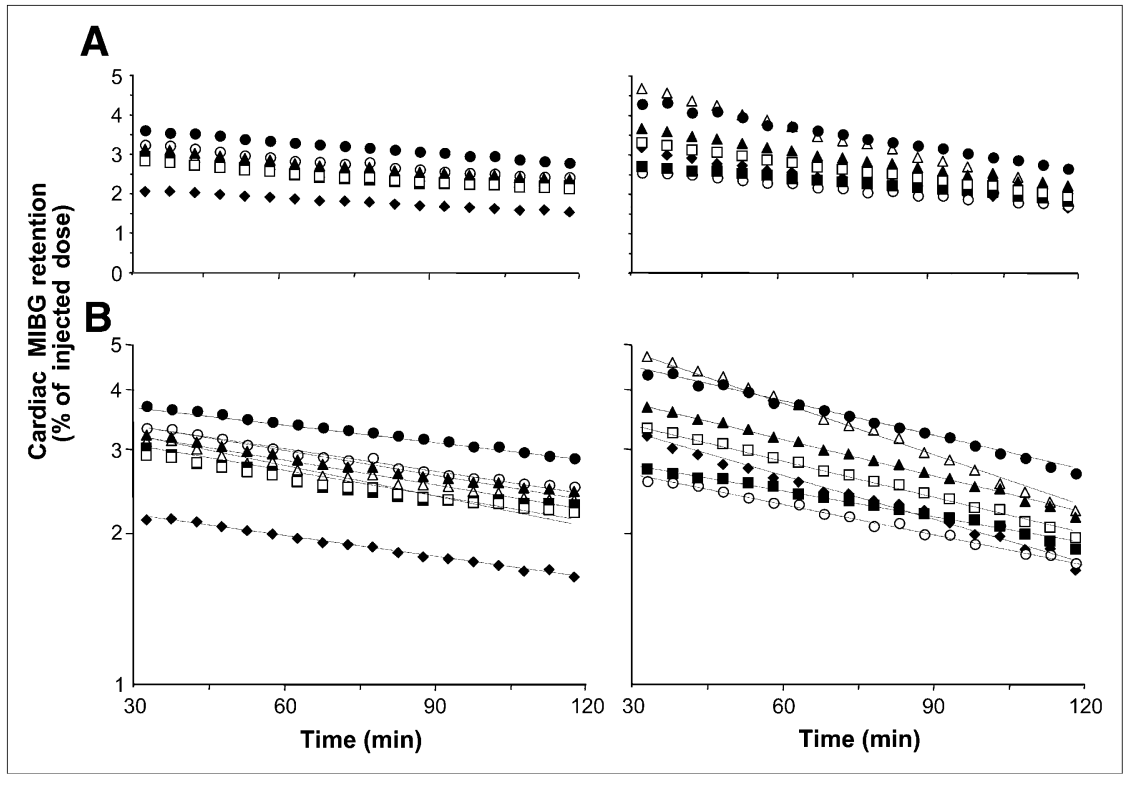

that this abnormality was associated with a reduction in heart and liver NET expression. These data extend previous studies focused on cardiac MIBG imaging and support the hypothesis that long-lasting diabetes results in a generalized dysfunction of the autonomic nervous system ultimately affecting the results of the method. In fact, the findings of the present study may explain the frequently reported paradoxic observation of normal tracer uptake early after injection in the diabetic myocardium, as opposite to subsequent accelerated washout.

\section{Accelerated Washout Versus Reduced Uptake}

Previous studies have already documented an altered MIBG handling in the diabetic heart. In a rat model of short-lasting (7 wk) diabetes, Kiyono et al. (18) documented heterogeneous MIBG activity at $3 \mathrm{~h}$ after injection, paralleled by a heterogeneous myocardial distribution of NET protein as opposed to homogeneous tissue perfusion. Our study extends these observations, showing that, in long-lasting (7 mo) non-insulin-dependent diabetes, the global (heart and liver) reduction in NET density is reflected not by reduced initial tracer uptake but rather by its accelerated washout. In fact, the initial dose retention of tracer was remarkably similar both in diabetic and in control mice (Table 2). This observation closely agrees with clinical literature ascribing significance to only late MIBG activity, as an index of cardiac sympathetic dysfunction in diabetes, neglecting early tracer uptake.
FIGURE 2. Liver time-activity curves of MIBG, depicted on linear scale (A) and on semilog scale (B). MIBG retention values, expressed as percentage of injected dose, are shown for control (left) and diabetic (right) mice. Early (30 min) uptake was similar for both groups of animals; by contrast, tracer washout was faster in diabetes.

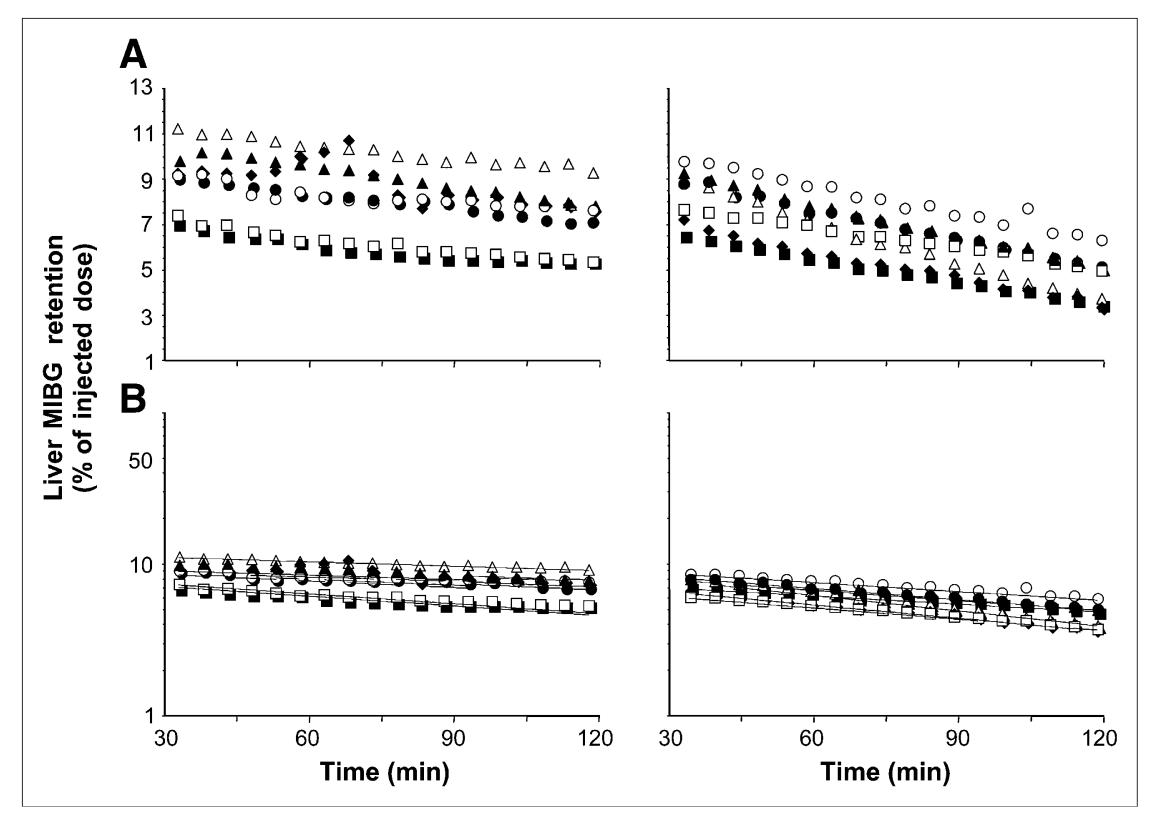




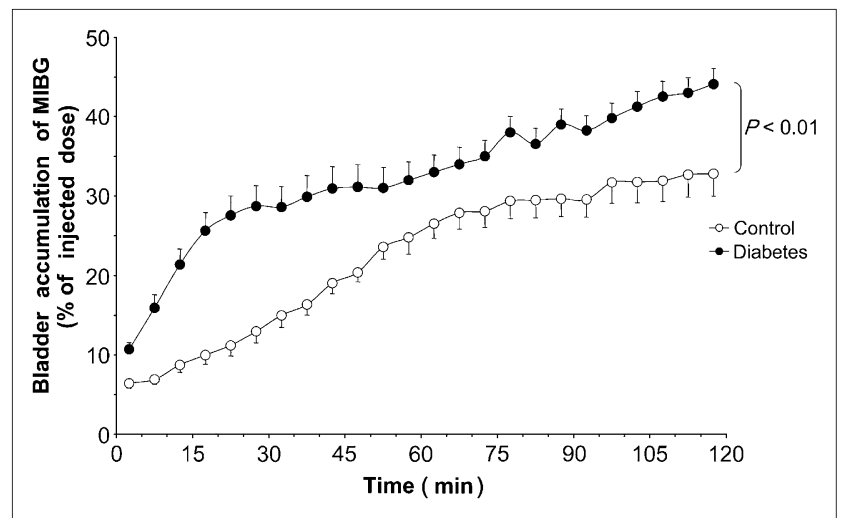

FIGURE 3. Bladder accumulation of MIBG, depicted on linear scale. MIBG accumulation curves, expressed as percentage of injected dose, are shown for control and diabetic mice. Data are mean \pm SEM.

If NET protein is the only mechanism for MIBG accumulation in synaptic vesicles, its reduction should simultaneously impair both steps of tracer kinetics, leading to a reduced initial uptake paralleled by an increased loss. Obviously, the preserved early myocardial activity might reflect a highly nonspecific tracer deposition soon after injection. However, in different disorders, such as Parkinson's disease, characterized by a severe loss of autonomic cardiac endings (26), a reduction of early MIBG uptake actually occurs. Similarly, left ventricular hypertrophy might have masked a reduced extraction fraction and thus a reduced early uptake in diabetic mice. However, diabetes did not induce myocardial hypertrophy in the present study.

Alternatively, the reduced NET function in diabetic myocardium might have been counterbalanced by an increased

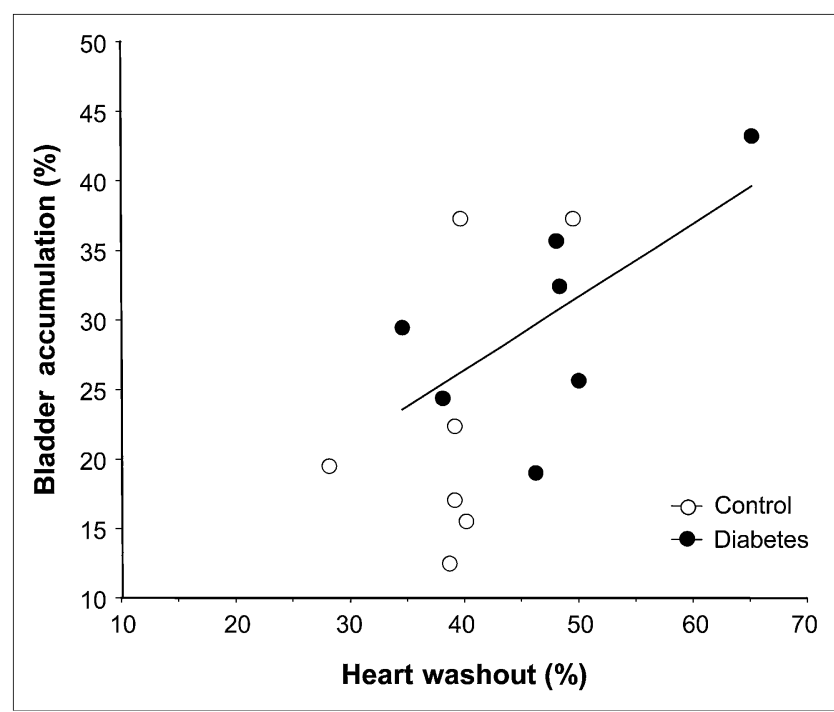

FIGURE 4. Relationship between heart washout and bladder accumulation. Data from control and diabetic mice are expressed as percentage of injected dose. Data are fitted by linear regression curve (black line, $r=0.73$ ).
TABLE 4

Analysis of NET Density

\begin{tabular}{|c|c|c|c|c|}
\hline \multirow[b]{2}{*}{ Parameter } & \multicolumn{2}{|c|}{$\begin{array}{l}\text { Control } \\
(n=7)\end{array}$} & \multicolumn{2}{|c|}{$\begin{array}{c}\text { Diabetes } \\
(n=7)\end{array}$} \\
\hline & Heart & Liver & Heart & Liver \\
\hline $\begin{array}{l}\mathrm{B}_{\max } \\
\text { (fmol/mg } \\
\text { of protein) }\end{array}$ & $244 \pm 10$ & $2,640 \pm 76$ & $136 \pm 18^{*}$ & $2,164 \pm 93^{*}$ \\
\hline $\mathrm{K}_{\mathrm{D}}(\mathrm{nmol} / \mathrm{L})$ & $9.3 \pm 0.7$ & $9.7 \pm 1.1$ & $9.4 \pm 2.5$ & $9.9 \pm 2.1$ \\
\hline \multicolumn{5}{|c|}{${ }^{\star} P<0.05$ vs. control values. } \\
\hline
\end{tabular}

arterial concentration of the tracer due to its reduced removal from the blood by whole-body tissues. Several data from our study seem to support this hypothesis. In agreement with the concept that diabetic autonomic neuropathy is a systemic process, although with different progression rates in different organs, in the present study MIBG washout and NET concentration were reduced in the heart and liver. In addition, and more important, diabetic animals displayed a marked increase in the rate of urinary MIBG elimination. Because diabetes is associated with reduced urinary elimination of catecholamines, this finding supports the view that an increased tracer concentration in the blood is available for renal clearance. On the other hand, tracer sequestration in the nonexchangeable urinary pool might represent the mechanism maintaining a high tissue-to-blood gradient in tracer concentration and thus the washout process. Accordingly, the correlation between urinary loss and cardiac washout of the tracer might indicate that the abnormal myocardial handling of MIBG can be part of a whole-body alteration of the autonomic system.

\section{Limitations}

The planar imaging used in the present study unfortunately prevented the assessment of arterial input function and thus any conclusion on the meaning of the different initial MIBG uptakes in the 2 groups of animals. The planarity of our nuclear imaging also prevented insight into the possible link between myocardial blood flow and MIBG handling; more information on this problem might have been obtained by using methods able to measure absolute flow (in $\mathrm{mL} / \mathrm{min} / \mathrm{g}$ of tissue). However, Kiyono et al. (18) has already observed that reduced NET expression is not associated with relative myocardial underperfusion.

In the present study, we used an experimental model of long-lasting chemically induced diabetes similar to human type II diabetes in terms of insulin responsiveness to sulfonylurea and insulin resistance $(23,24)$. However, great caution should be used in extending the present results to diabetic patients. Nevertheless, our findings suggest the opportunity of investigating NET expression in diabetic patients as a possible correlate of MIBG washout and a potential target of therapeutic interventions. 
Finally, because the imaging study immediately preceded organ sampling and assay of NET, we did not evaluate myocardial perfusion. Adding a second isotope might have hampered a detailed description of MIBG kinetics in the different organs. However, to the best of our knowledge, abnormalities in myocardial blood flow under resting conditions have not been described so far in diabetic models or patients. Obviously, we are well aware that flow distribution might be inhomogeneous in these animals. However, the focus of our study was not to determine the relationship between flow distribution and MIBG handling throughout the myocardium.

\section{CONCLUSION}

The present study documented that in a murine model of long-lasting streptozotocin-induced non-insulin-dependent diabetes mellitus, myocardial and liver handling of MIBG are characterized by accelerated washout. This phenomenon seems caused by a generalized reduced expression of NET in the whole body, possibly in agreement with the progressive and generalized nature of diabetic autonomic neuropathy (22). The effect of such a generalized disorder increases the bioavailability of the tracer, allowing for a "normal" initial uptake by the heart.

These findings might explain the paradoxic association between normal early cardiac uptake of the tracer and marked impairment in its retention. The acceleration in myocardial tracer washout observed in our diabetes model supports the view that the major fingerprint of cardiac diabetic neuropathy is, at least initially, the reduction in neuronal reuptake of norepinephrine rather than the loss of neuronal endings. If confirmed in a clinical setting, these data might indicate that the estimation of quantitative indices of MIBG kinetics might improve our insight into the mechanisms of autonomic nerve dysfunction and its role in diabetes.

\section{ACKNOWLEDGMENTS}

This work was supported by grants from Consiglio Nazionale delle Ricerche and Scuola Superiore Sant'Anna. All experiments, inclusive of ethics approval, complied with the current Italian laws. We thank Irene D'Aragona for technical assistance, Ilaria Russo for assistance with the radioligand binding experiments, and Cecilia Ciampi for assistance with animal care.

\section{REFERENCES}

1. Rathman W, Ziegler D, Jahnke M, Haastert B, Gries FA. Mortality in diabetic patients with cardiovascular autonomic neuropathy. Diabet Med. 1993; 10:1820-1824.
2. Ewing DJ, Campbell IW, Clarke BF. The natural history of diabetic autonomic neuropathy. $Q$ J Med. 1980;49:95-108.

3. Zola B, Kahn JK, Juni JE, Vinik AI. Abnormal cardiac function in diabetic patients with autonomic neuropathy in the absence of ischemic heart disease. J Clin Endocrinol Metab. 1986;63:208-214.

4. Gerritsen J, Dekker JM, TenVoorde BJ, et al. Impaired autonomic function is associated with increased mortality, especially in subjects with diabetes, hypertension, or a history of cardiovascular disease: the Hoorn Study. Diabetes Care. 2001;24:1793-1798.

5. Nagamachi S, Fujita S, Nishii R, et al. Prognostic value of cardiac I-123 metaiodobenzylguanidine imaging in patients with non-insulin-dependent diabetes mellitus. J Nucl Cardiol. 2006;13:34-42.

6. Hattori N, Tamaki N, Hayashi T, et al. Regional abnormality of iodine-123MIBG in diabetic hearts. J Nucl Med. 1996;37:1985-1990.

7. Hattori N, Schwaiger M. Metaiodobenzylguanidine scintigraphy of the heart: what have we learnt clinically? Eur J Nucl Med. 2000;27:1-6.

8. Merlet P, Valette H, Dubois-Rande JL, et al. Iodine 123-labeled metaiodobenzylguanidine imaging in heart disease. J Nucl Cardiol. 1994;1(suppl):S79-S85.

9. Wieland DM, Brown LE, Rogers WL, et al. Myocardial imaging with a radioiodinated norepinephrine storage analog. J Nucl Med. 1981;22:22-31.

10. Nakajo M, Shimabukuro K, Yoshimura H, et al. Iodine-131 metaiodobenzylguanidine intra- and extravesicular accumulation in the rat heart. $J$ Nucl Med. 1986;27:84-89.

11. Sisson JC, Wieland DM, Sherman P, Mangner TJ, Tobes MC, Jacques S Jr. Metaiodobenzylguanidine as an index of the adrenergic nervous system integrity and function. J Nucl Med. 1987;28:1620-1624.

12. Tobes MC, Jaques S Jr, Wieland DM, Sisson JC. Effect of uptake-one inhibitors on the uptake of norepinephrine and metaiodobenzylguanidine. J Nucl Med. 1985;26:897-907.

13. Glowniak JV, Kilty JE, Amara SG, Hoffman BJ, Turner FE. Evaluation of metaiodobenzylguanidine uptake by the norepinephrine, dopamine and serotonin transporters. J Nucl Med. 1993;34:1140-1146.

14. Degrado TR, Zalutsky MR, Vaidyanathan G. Uptake mechanisms of meta$\left[{ }^{123}\right.$ I] iodobenzylguanidine in isolated rat heart. Nucl Med Biol. 1995;22:1-12.

15. Ungerer $M$, Weig $\mathrm{HJ}$, Kübert $\mathrm{S}$, et al. Regional pre- and postsynaptic sympathetic system in the failing human heart: regulation of $\beta$ ARK-1. Eur $J$ Heart Fail. 2000;2:23-31.

16. Sugiyama T, Kurata C, Tawarahara K, Nakano T. Is abnormal iodine-123-MIBG kinetics associated with left ventricular dysfunction in patients with diabetes mellitus? J Nucl Cardiol. 2000;7:562-568.

17. Shouda S, Mikami T, Wakabayashi Y, et al. Comparison of $\left[{ }^{123} I\right]$ metaiodobenzylguanidine kinetics with heart rate variability and plasma norepinephrine level. J Nucl Cardiol. 1997;4:515-523.

18. Kiyono Y, Iida Y, Kawashima H, Ogawa M, Tamaki N, Nishimura H. Norepinephrine transporter density as a causative factor in alterations in MIBG myocardial uptake in NIDDM model rats. Eur J Nucl Med Mol Imaging. 2002;29:999-1005.

19. Kiyono Y, Kanegawa N, Kawashima H, et al. A new norepinephrine transporter imaging agent for cardiac sympathetic nervous function imaging: radioiodinated (R)-N-methyl-3-(2-iodophenoxy)-3-phenylpropanamine. Nucl Med Biol. 2003; 30:697-706.

20. Kiyono Y, Kajiyama S, Fujiwara H, Kanegawa N, Saji H. Influence of the polyol pathway on norepinephrine transporter reduction in diabetic cardiac sympathetic nerves: implications for heterogeneous accumulation of MIBG. Eur J Nucl Med Mol Imaging. 2005;32:438-442.

21. Carrio I. Cardiac neurotransmission imaging. J Nucl Med. 2001;42:1062-1076.

22. Vinik AI, Maser RE, Mitchell BD, Freeman R. Diabetic autonomic neuropathy. Diabetes Care. 2003;26:1553-1579.

23. Wei M, Ong L, Smith MT, et al. The streptozotocin-diabetic rat as a model of the chronic complications of human diabetes. Heart Lung Circ. 2003;12:44-50.

24. Masiello P. Animal models of type 2 diabetes with reduced pancreatic $\beta$-cell mass. Int J Biochem Cell Biol. 2006;38:873-893.

25. Lee CM, Javitch JA, Snyder SH. Characterization of $\left[{ }^{3} \mathrm{H}\right]$ desipramine binding associated with neuronal norepinephrine uptake sites in rat brain membranes. J Neurosci. 1982;2:1515-1525.

26. Taki J, Nakajima K, Hwang EH, et al. Peripheral sympathetic dysfunction in patients with Parkinson's disease without autonomic failure is heart selective and disease specific. Eur J Nucl Med. 2000;27:566-573. 